\title{
Biosynthesis and Characterization of Zinc Oxide Nanoparticles using Root Extract of Zingiber officinale
}

\author{
L.F.A. ANAND RAJ* and E. JAYALAKSHMY \\ Department of Biotechnology, St. Joseph's College of Engineering, OMR, Chennai, India. \\ ${ }^{*}$ Corresponding author E-mail: anandlfa@yahoo.co.in \\ http://dx.doi.org/10.13005/ojc/310105
}

(Received: November 28, 2014; Accepted: January 11, 2015)

\begin{abstract}
The synthesis of $\mathrm{ZnO}$ nanoparticles using biological method is always eco friendly and attractive. The current study focuses on the production of $\mathrm{ZnO}$ nanoparticles using the aqueous root extracts of Zingiber officinale (ginger). The root extracts were found to be rich in flavonoids which were confirmed by the flavonoid test thereby enhancing the biogenic synthesis of $\mathrm{ZnO}$ nanoparticle. The Scanning Electron Microscope with the Energy Dispersive X-ray studies were used for characterization that provides the size and the elemental composition of the synthesized $\mathrm{ZnO}$ nanoparticles. The average size of the nanoparticles was found to be $30-50 \mathrm{~nm}$. The FTIR analysis played a pivotal role in displaying the important functional groups present in the $\mathrm{ZnO}$ nanoparticle, which showed that the sample had strong absorbance in the range of $1600-$ $1450 \mathrm{~cm}^{-1}$. Hence the biogenic synthesis of ZnO nanoparticles using Zingiber officinale, can be an alternative to chemical synthesis.
\end{abstract}

Key words: Zinc oxide nanoparticles, Zingiber officinale, Green synthesis, Electron microscope.

\section{INTRODUCTION}

Metal nanoparticles have attained a great importance due to their unique feature such as catalytic, magnetic, optical and electrical properties $^{1-2}$. They have distinct or completely new properties when compared to their bulk counterpart, which draws the entire scientific researcher to focus on their synthesis ${ }^{3}$. Several metal nanoparticles such as silver, copper, gold, iron etc., has been explored so far. Since much research has been done already in those metal nanoparticles, the current study focused on zinc oxide nanoparticle. Zinc oxide is considered as multi-task metal oxide which can be used as nanoscale due to its unique physical, chemical and biological properties ${ }^{4}$. Zinc oxide nanoparticles has a wide application in various fields such as optical, piezoelectric, mechanical, thermodynamic, electrodynamic, electromagnetic and gas sensing ${ }^{3,5,6}$. It is also used as sensor, photo catalyst in the production of hydrogen, as fillers in rubber industry etc as they 
have enhanced pyroelectric properties ${ }^{6}$. They also find applications in the pharmaceutical industry, cosmetic industry, solar cells and also as semiconductors ${ }^{7}$. Furthermore, zinc oxide nanoparticle also act as good antimicrobial agent as they show antimicrobial activity against many pathogenic organisms like Eschericia coli, Pseudomonas aeruginosa, Campylobacter jejuni, etc $^{8}$. When compared with other nanoparticles $\mathrm{ZnO}$ nanoparticles are less toxic and safe so they find increased applications in industries like food where they are used in packaging and processing of meat and vegetables.

The conventional methods of synthesizing nanoparticles using chemical method were found to be more expensive and also involve the use of toxic, hazardous chemicals that are responsible for various biological risks ${ }^{9}$. In order to avoid the use of toxic chemicals, scientists have developed better methods which can be done in two ways. First one is the use of microorganisms such as bacteria, fungi and yeas $\mathrm{t}^{10}$. Using microorganism for the synthesis of nanoparticle were found to be more tedious and require more steps in maintaining cell culture, intracellular synthesis with more purification steps while the second one is with the use of plants known as the 'Green synthesis' or 'biogenic synthesis. This type of biosynthesis shows better advancement over chemical and physical method as it is lesser toxic, cost effective, environmental friendly ${ }^{2}$ and also involves proteins as capping agents ${ }^{7}$. Proteins are biomolecules and are advantageous by giving low toxic degradable end products ${ }^{11}$. Hence biogenic synthesis of nanoparticle was found to be more attractive for research as conventional methods are more expensive and non-ecofriendly.

Ginger (Zingiber officinale Roscoe, Zingiberaceae) is among the most frequently and heavily consumed dietary condiments throughout the world. It is extensively used in ayurvedic medical and has a long history of at least 2500 years as a digestive aid and antinausea remedy. Ginger is frequently prescribed by Indian and Chinese medicine for the treatment of cough, common cold, rheumatism, snake bite and respiratory problems ${ }^{11}$. It is also used in the treatment of colorectal cancer, treating skin diseases, cough, heart palpitation, swelling, dyspepsia and loss of appetite ${ }^{3}$.
Chemically, ginger is rich in flavonoids and polyphenolic compounds such as gingerols, shagols, zingerone, paradol, terphineol, terpenes, borneol, geraniol, limonene, linalool, alphazingiberene etc $^{12}$. Recent studies revealed that ginger can be used for the synthesis of nanoparticle. Singh et al., ${ }^{3}$ has reported that aqueous extract of ginger was used for the synthesis of gold and silver nanoparticles. Hence the present study was undertaken in order to evaluate the efficacy of Zingiber officinale for the biogenic synthesize of $\mathrm{ZnO}$ nanoparticle.

\section{MATERIALS AND METHODS}

Zinc acetate dihydrate $\left(\mathrm{Zn}\left(\mathrm{CH}_{3} \mathrm{COO}\right)_{2}\right.$. $\left.2 \mathrm{H}_{2} \mathrm{O}\right)$ and sodium hydroxide $(\mathrm{NaOH})$ was purchased from Fisher Scientific. The glasswares were washed and sterilised before use. Deionized water was used for the synthesis and for the preparation of root extract. The protocol for the synthesis was followed according to Singh et al., and Gnanasangeetha et al., ${ }^{3,13}$.

\section{Preparation of the root extract}

Fresh ginger was collected from the local market. Ginger was washed well and was soaked in water in order to remove the contaminants present in the skin. The roots were then air dried completely to remove the moisture content from it. Dried ginger was taken and the outer skin was peeled off which were then weighed $(5 \mathrm{~g})$. It was cut into pieces and kept in hot air oven at $50^{\circ} \mathrm{C}$ for about an hour. The dried roots were taken and crushed in a mortar and pestle by slowly adding $25 \mathrm{ml}$ of deionised water. The extract was filtered using Whatman No.1 Filter paper. The extract was stored at $4^{\circ} \mathrm{C}$ for further use.

\section{Test for flavonoids}

The root extracts were tested for flavonoids which were determined by the method of Harbone ${ }^{14}$. Lead acetate test was performed by adding $1 \mathrm{ml}$ of the root extract with few drops of $10 \%$ lead acetate was added. A yellow precipitate was seen. Sodium hydroxide test was performed by adding $1 \mathrm{ml}$ of the root extract with $1.0 \mathrm{M}$ of $\mathrm{NaOH}$. It was stirred for 1 minute until a deep yellow coloured precipitate was observed. Lead acetate test was performed by adding $1 \mathrm{ml}$ of root extract with few drops of $10 \%$ of $\mathrm{FeCl}_{3}$ when a blackish red precipitate appeared. 


\section{Preparation of zinc oxide nanoparticles}

$50 \mathrm{ml}$ of $0.01 \mathrm{M}$ Zinc acetate dihydrate was prepare using deionised water. To this $500 \mu \mathrm{l}$ of root extract was added slowly by continuous stirring in a magnetic stirrer. In order to maintain the $\mathrm{pH} 12$, 1.0 $\mathrm{M}$ sodium hydroxide was used. After reaching the desired $\mathrm{pH}$ the mixture was allowed in the stirrer for 2 hours until the formation of white precipitate was observed. This mixture was centrifuged at $10,000 \mathrm{rpm}$ for 10 minutes. The pellet was washed using deionised water and dried at $100^{\circ} \mathrm{C}$ in hot air oven for overnight. The resulting white powder was collected carefully for characterization ${ }^{13}$.

\section{Characterization of zinc oxide nanoparticles}

Size and shape of the synthesized Zinc
Oxide nanoparticle were examined by FESEM by Carl Zeiss Supra 55 (Germany) microscope. Element analysis was obtained from energy dispersive X-ray diffraction (EDX), which was attached with FESEM. FTIR Spectroscopy was measured using Perkin Elmer1 Spectrum FT-IR in the scanning range $450-4000 \mathrm{~cm}^{-1}$.

\section{RESULTS AND DISCUSSION}

The results of the Flavonoid test for the root extracts were shown in Table 1. The presence of flavonoids were observed in the root extract and denoted by the symbol '+'. Similar results were also observed in earlier studies ${ }^{13}$.

Table 1: Flavonoid tests of the root extracts of Zingiber officinale

\begin{tabular}{llc}
\hline Name of the test & Observation & Result \\
\hline Lead acetate test & Yellow precipitate & + \\
Sodium Hydroxide Test & Deep yellow precipitate & + \\
Ferric chloride test & Blackish red precipitate & + \\
\hline
\end{tabular}

The structure, shape and size of the synthesized $\mathrm{ZnO}$ nanoparticles were analysed by SEM and Fig 1\&Fig 2 shows the same with the average size of the nanoparticle being 30-50nm and were spherical in shape. According to Singh et. al. ${ }^{3}$ the size of the synthesized $\mathrm{ZnO}$ nanoparticles was in the range of $5-40 \mathrm{~nm}$ which were in relevance to the results obtained in the present study. From the SEM image it is clear that the shape of the $\mathrm{ZnO}$ nanoparticle is spherical and this also matched with the earlier studies ${ }^{2-3}$.

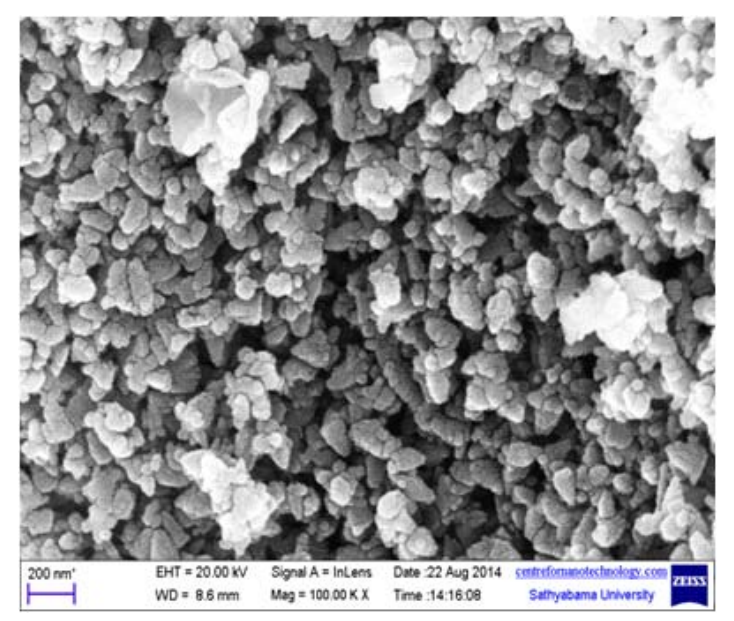

Fig. 1- 2: SEM images of Zinc oxide nanoparticle using Zingiber officinale 
The Energy dispersive X-ray Diffractive (EDX) study was carried out for the synthesized ZnO nanoparticles (Figure 3 ) to know about the elemental composition. EDX confirms the presence of element zinc and oxygen signals of zinc oxide nanoparticle and this analysis showed the peaks that corresponded to the optical absorption of the produced nanoparticle. The elemental analysis of the nanoparticle yielded $80 \%$ of Zinc and $19 \%$ of oxygen which proves that the produced nanoparticle is in its highest purified form and also was in agreement with the earlier studies ${ }^{15}$.

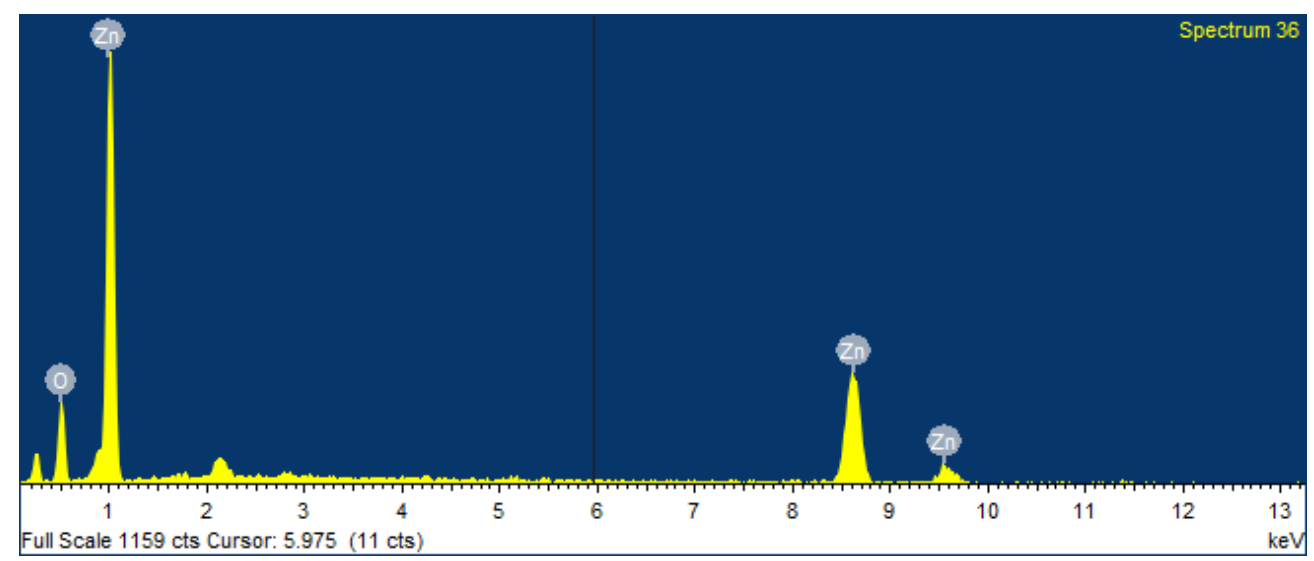

Fig. 3: EDX image of the synthesized ZnO nanoparticle

FT-IR pattern of the synthesized nanoparticle were studied (Figure 4) and it ranges from $450-4000 \mathrm{~cm}^{-1}$. A strong absorption of the Zinc oxide nanoparticle was seen at $1566 \mathrm{~cm}^{-1}$. The absorption at this range confirms the presence of $8.43 \%$ of $\mathrm{N}-\mathrm{H}$ bonds. The $\mathrm{C}=\mathrm{C}$ bonds were seen at $2172 \mathrm{~cm}^{-1}$, the $\mathrm{O}-\mathrm{H}$ bond stretching at $3417 \mathrm{~cm}^{-1}$ and the $\mathrm{C}-\mathrm{H}$ bond stretching at $1414 \mathrm{~cm}^{-1}$. According to Sangeetha et. al.,(7) there was a strong absorption at $528 \mathrm{~cm}^{-1}$ and there were peaks at 3451,1552 , 2170 and $1399 \mathrm{~cm}^{-1}$ which corresponds to the $-\mathrm{OH}$, $\mathrm{N}-\mathrm{H}, \mathrm{C}=\mathrm{C}$ and $\mathrm{C}-\mathrm{H}$ bond stretching respectively. The presence of alkenes in the root extracts may have mediated the reduction of $\mathrm{ZnO}$ nanoparticle ${ }^{7 \& 13}$. Similar kind of peaks were observed in the present study and proved the presence of $\mathrm{ZnO}$ nanoparticles which were in accordance with the earlier reports.

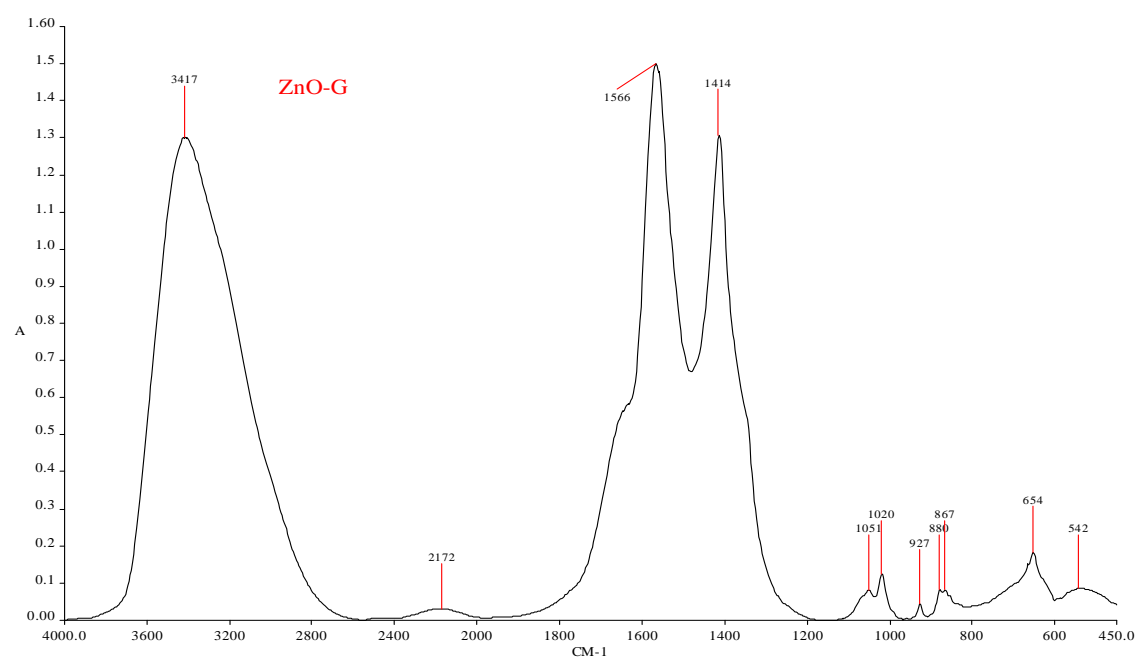

Fig. 4: FT-IR pattern of the synthesized nanoparticle 


\section{CONCLUSION}

It is evident from the present study that the biogenic synthesis of $\mathrm{ZnO}$ nanoparticle is eco friendly, simple and efficient than the conventional method with the less usage of toxic chemicals. The characterisation of $\mathrm{ZnO}$ nanoparticle with SEM showed a spherical shape with an average size of $30-50 \mathrm{~nm}$ conforms the ability of ginger extract to synthesize the $\mathrm{ZnO}$ nanoparticle. The EDX results display the expected percentage of zinc and oxygen, while FTIR peaks confirmed the presence of chemical bonds that showed the involvement of ginger in the production of nanoparticle. The mechanism by which these ginger extract are responsible for the synthesis of nanoparticle was not clear. Hence it is justifiable to conclude from the earlier reference that the synthesis is due to the presence of polyphenolic compound, flavonoids that mediate the synthesis of $\mathrm{ZnO}$ nanoparticle. Thus the $\mathrm{ZnO}$ nanoparticles produced from Zingiber officinale are expected to have extensive applications in various industries.

\section{ACKNOLEDGEMENTS}

The authors extend their sincerest thanks to the management and staff of St. Josephs College of Engineering, Chennai for providing the facilities in carrying out the work.

\section{REFERENCES}

1 Garima, S.; Bhavesh, R.; Kasariya, K.; Ranjan, A.S.; Singh, R.P. Biosynthesis of silver nanoparticles using Ocimum sanctum (Tulsi) leaf extract and screening its antimicrobial activity, J Nanopart Res, 2011, 13:2981-2988.

2 Vidhya, C.; Shilpa, H.; Chandraprabha, M.N.; Antonyraj, M.A.L.; Indu, V.G.; Aayushi, J.; Bansal, K. Green synthesis of Zinc Oxide Nanoparticles by Calotropis gigantea, IJCET, 2013, 118-120.

3 Singh, R.P.; Magesh, S.; Rakkiyappan, C. Ginger (Zingiber officinale) root extract: a source of silver nanoparticles and their application, IJBEST, 2011, 02,75-80.

4 Hasna, A.S.; Rajeshwari, S.; Venckatesh, R.Green synthesis and characterization of zinc oxide nanoparticles from Ocimum basilicum L. var. purpurascens Benth.Lamiaceae leaf extract, Mater lett, 2014,131, 16-18.

5 Thirumavalavan, M.; Huang, K.; Lee, J. Preparation and Morphology Studies of Nano Zinc Oxide Obtained Using Native and Modified Chitosans, Materials , 2013,6, 4198-4212.

Radzimska, A.K; Jesionowski, T. Zinc Oxide-From Synthesis to Application: A Review, Materials, 2014, 7, 2833-2881.
R. Green synthesis of zinc oxide nanoparticles by aloe barbadensis miller leaf extract: Structure and optical properties, Mater. Res. Bull. , 2011, 46, 25602566.

$8 \quad$ Xie, Y.; He, Y.; Peter, L.I.; Jin, T.; Shi, X. Antibacterial Activity and Mechanism of Action against Campylobacter jejuni, Appl. Environ. Microbiol, 2011,77, 2325-2231.

9 Geoprincy G, Vidhya srri B N, Poonguzhali $U$, Nagendra G N, Renganathan S A review on green synthesis of silver nanoparticles, Asian J Pharm Clin Res, 2013, 6, 8-12.

10 Helan, J.C.; Anand Raj, L.F.A.; Namasivayam, S.K.R.; Bharani, R.S.A. Improved pesticidal activity of fungal metabolite from Nomureae rileyi with chitosan nanoparticles, ICANMEET, IEEE, 2013, 387-390.

11 Raja, S.K.N.; Anand Raj, L.F.A.; Robin, A.T.G.; Helan, J.C.; Arvind, R.S.B. Optimal Synthesis OF Biocompatible Bovine Serum Nanoparticles- Incorporated Quercetin (BSA NPS-QT) Nano Drug Conjugate for the Controlled Release and Improved Anti Oxidative Activity, Res.J. Pharm., Biol. Chem. Sci., 2014, 5, 478-487.

12 Ghosh, A.K.; Banerjee, S.; Mullick, H.I.; Banerjee, J. Zingiber officinale: A Natural Gold , International Journal of Bioengineering Sciences, 2011, 2, 283-294. 
13 Gnanasangeetha, D., Sarala, T.D. Biogenic Production of Zinc Oxide Nanoparticle using Acalypha indica', J. Chem. Bio. Phy. Sci, 2013, 4, 238-246.

14 Harbone, J.B. Phytochemical Methods, A Guide to Modern Techniques of Plant Analysis, Chapman and Hall Publication, 1973 London

15 Sangeetha, N.; Kuppusamy, K. A. Extracellular of zinc oxide nanoparticle using seaweeds of Gulf of Mannar, India, Journal of Nanobiotechnology, 2013, 1-3.

16 Singh, R.P.; Vineet, K.S.; Yadav, R.S.; Singh, P.K.; Pandey, A.C. Biological approach of zinc oxide nanoparticles formation and its characterization, Adv. Mat. Lett., 2011, 2,313317.

17 Kavitha, K.S.; Syed, B.; Rakshith, D.; Kavitha, H.U.; Rao, Y.H.C.; Harini, B.P.; Satish, S. Plants as Green Source towards Synthesis of Nanoparticles', Int. Res. J. Biological. Sci., 2013, 2, 66-76.

18 Hasan, H.A.; Rasheed, R.A.M.; Basama, M.A.R.; Hassan, R.B.A. Chemical Composition and Antimicrobial Activity of the Crude Extracts Isolated from Zingiber officinale by Different Solvents, Pharmaceut Anal Acta, 2012, 3,1-5.

19 AbdElhady, M.M. Preparation and Characterization of Chitosan/Zinc Oxide Nanoparticles for Imparting Antimicrobial and UV Protection to Cotton Fabric, International Journal of Carbohydrate Chemistry 2012, 2012,1-6.

20 Aswathi, S.C.V.; Jovitta, J.C.; Suja, S. Synthesis of $\mathrm{ZnO}$ nanoparticles from Alpinia purpurata and their antimicrobial properties, Res. J. Pharm. Biol. Chem. Sci., 2012, 3, 1206-1213.

21 Becheri, A.; Du"rr, M.; Nostro, P.L.; Baglioni, P. Synthesis and characterization of zinc oxide nanoparticles: application to textiles as UV-absorbers, J. Nanopart. Res, 2008,
10,679-689.

22 Ghasemzadeh, A.; Hawa, Z.E.J.; Asmah, R. Antioxidant Activities, Total Phenolics and Flavonoids Content in Two Varieties of Malaysia Young Ginger (Zingiber officinale Roscoe), Molecules, 2013, 15, 4324-4333.

23 Lee, C.W.; Shaily, M.; Katherine, Z.; Dongli.; Yu-chang tsai.; Janet, B.; Pedro, J.J.A. Developmental phytotoxicity of metal oxide nanoparticles to Arabidopsis thaliana', Environ Toxicol Chem, 2013, 29,669-675.

24 Meenu, S.; Suman, J. Comparison of antioxidant activity of Andrographis paniculata and Tinospora cordifolia leaves, J. Curr. Chem. Pharm. Sc, 2011, 1, 1-8.

25 Moghaddam, A.B.; Nazari, T.; Badraghi, J.; Kazemzad, M. Synthesis of $\mathrm{ZnO}$ Nanoparticles and Electrodeposition of Polypyrrole/ZnO Nanocomposite Film, Int. J. Electrochem. Sci., 2009, 4, 247-257.

26 Sangeetha, G.; Rajeshwari, S.; Venckatesh, R. Green synthesized $\mathrm{ZnO}$ nanoparticles against bacterial and fungal pathogens, Progress in natural science Materials International 2012, 22,693-700.

27 Satyanarayana, T.; Srinivasa, R.K.; Nagarjuna, G. Synthesis, Characterization, and Spectroscopic Properties of $\mathrm{ZnO}$ Nanoparticles, ISRN Nanotechnology, 2012, 2012, 1-6.

28 Surabhi, S.K.; Venkateswarlu, P.; Rao, V.R.; Rao, G. Synthesis, characterization and optical properties of zinc oxide nanoparticles, Int. Nano Lett., 2013,3,1-6.

Vadlapudi, V.; Kaladhar, D. S. V. G. K. Review: Green Synthesis of Silver and Gold Nanoparticles, Middle -East J. Sci. Res., 2014, 19,834-842.

30 Singh, C.; Sharma, V.; Naik, P.K.R.; Kandhelwal, V.; Singh, H. A Green Biogenic Approach for Synthesis of Gold and Silver Nanoparticles using Zingiber officinale, Dig J Nanomater Bios, 2011, 6, 535-542. 